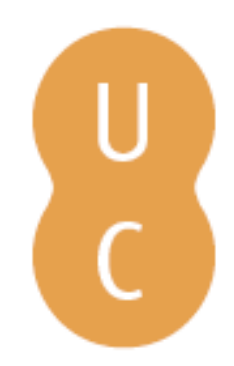

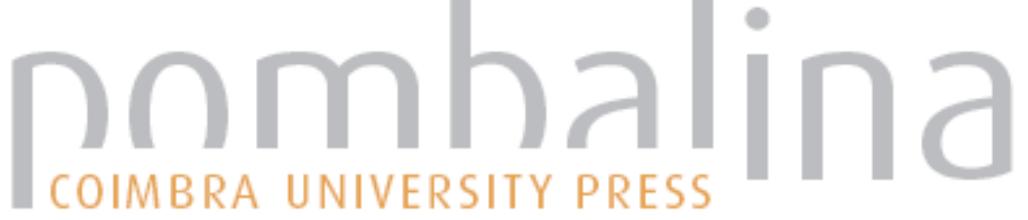

\section{Wind measurement accuracy in fire experiments}

Autor(es): $\quad$ Pimont, François; Dupuy, Jean-Luc; Linn, Rodman R.; Parsons, Russ

Publicado por: Imprensa da Universidade de Coimbra

URL

persistente: URI:http://hdl.handle.net/10316.2/44595

DOI: $\quad$ DOI:https://doi.org/10.14195/978-989-26-16-506_78

Accessed : $\quad$ 26-Apr-2023 11:00:35

A navegação consulta e descarregamento dos títulos inseridos nas Bibliotecas Digitais UC Digitalis, UC Pombalina e UC Impactum, pressupõem a aceitação plena e sem reservas dos Termos e Condições de Uso destas Bibliotecas Digitais, disponíveis em https://digitalis.uc.pt/pt-pt/termos.

Conforme exposto nos referidos Termos e Condições de Uso, o descarregamento de títulos de acesso restrito requer uma licença válida de autorização devendo o utilizador aceder ao(s) documento(s) a partir de um endereço de IP da instituição detentora da supramencionada licença.

Ao utilizador é apenas permitido o descarregamento para uso pessoal, pelo que o emprego do(s) título(s) descarregado(s) para outro fim, designadamente comercial, carece de autorização do respetivo autor ou editor da obra.

Na medida em que todas as obras da UC Digitalis se encontram protegidas pelo Código do Direito de Autor e Direitos Conexos e demais legislação aplicável, toda a cópia, parcial ou total, deste documento, nos casos em que é legalmente admitida, deverá conter ou fazer-se acompanhar por este aviso. 


\section{ADVANCES IN}

\section{FOREST FIRE RESEARCH}

\section{8}

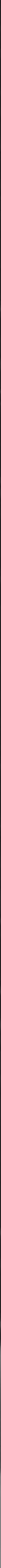




\title{
Wind measurement accuracy in fire experiments
}

\author{
François Pimont ${ }^{1 *}$; Jean-Luc Dupuy ${ }^{1}$; Rodman R. Linn² ${ }^{2}$ Russ Parsons ${ }^{3}$ \\ ${ }^{1}$ URFM INRA.84914 Avignon, France, \{francois.pimont@inra.fr*, jean-luc.dupuy@inra.fr\} \\ ${ }^{2}$ EES, LANL, Los Alamos, NM 87544, USA, \{rrl@lanl.gov\} \\ ${ }^{3}$ USFS RMRS, Fire Sciences Lab.MT 5775, USA, \{rparsons@fs.fed.us\}
}

\begin{abstract}
Fire experiments generally aim to relate fire behavior to fuel and weather conditions. One of the main factors influencing the fire rate of spread is the wind speed, but its measurement in fire experiments is challenging due to the combination of wind-flow turbulence and the remote location of the sensors relative to the fire front. Differences arise because i) the feedbacks of the fire plume on the ambient wind modify the wind speed at fire location, ii) the environment at the measurement location may differ from the fire plot characteristics in non-uniform conditions (fuel, topography), which may induce a spatial bias between mean winds and iii) instantaneous fluctuations at both locations are weakly correlated, which affects the representativeness of wind measurement, because of the relatively brief duration of fire experiments.

The present work disentangles the sources of bias and variability in wind measurements (ii and iii), and provides understanding of wind measurement accuracy in fire experiments. The combination of both measurement error sources, both in representativeness and spatial bias, has to date never been studied. In the present study, we employed a modelling approach using HIGRAD/FIRETEC to compute Large-EddySimulations (LES) of wind flows over typical fire experiments. Our simulations show that the spatial bias resulting from the distance to the trailing edge of the measurement location, can be very strong in a realistic configuration and that $7 h$ (with $h$ the canopy height) is too short to get measurements representative of the ambient open wind. In this context, we recommend that the distance to the trailing edge is measured and the upwind canopy characterized (at least in terms of height), so that horizontal Wind Adjustment Factor can be applied to correct the measured wind. Another source of bias is the fact that the fire wind, defined as the average wind at $20 \mathrm{ft}$ above the fire plot, can be altered by the presence of the upwind safety break, when its size is larger than 6 to $7 h$.

The representativeness of wind measurements can be estimated by comparing values of fire and measured winds corresponding to replicates of virtual fire experiments. We confirm the finding of two pioneering studies on wind measurement representativeness, which already suggested that measurement errors resulting from both uncertainties in both measured and fire wind could be very significant in typical fire experiments, especially when the plot size was small, when the experiment duration was short, and when the number of sensors was small. For our preliminary results, obtained in more realistic configurations, we found that square fire plots larger than $200 \mathrm{~m}$ and a number of five sensors seem to provide a reasonable measurement accuracy, provided that the fire does not spread too fast (which would result in shorter experiment duration) and that the wind is not too low (as the measurement representativeness increases with ambient wind speed).
\end{abstract}

Keywords: Fire metrology, Measurement accuracy, Bias, Variance, FIRETEC, Fire behavior

\section{Introduction}

Fire experiments generally aim to relate fire behavior to fuel and weather conditions. One of the main factors influencing fire rate of spread is the wind speed. However, empirical relationships generally exhibit significant variability, which can partly be explained by wind measurement accuracy (Cruz and Alexander 2013). Indeed, measuring the wind in fire experiments is challenging, due to the combination of differences in the turbulent nature of wind flow and the location of sensor(s). In practice, the ambient wind speed is measured at some distance from the fire front, so the wind speed at the measurement location often differs from the wind speed at the fire location. 
Because no evidence was found that instantaneous measured wind relates to variations in fire spread (Cheney et al. 1993; Taylor et al. 2004), measured wind speed is generally averaged over the experiment duration and eventually, over the different sensors when exist. The rationale for that process is that the average measured wind is a good representative for the ambient wind, which drives the fire within the experimental plot. However, some differences between measured and fire wind arise because i) the feedbacks of the fire plume on the ambient wind modify the wind speed at fire location, ii) the local or upwind environment may differ (fuel, topography), which may induce differences between mean winds, and/or iii) instantaneous fluctuations at both locations are weakly or not correlated, which affects the representativeness of wind measurements.

The fire feedbacks on the fire wind are generally not included in wind measurement error (Sullivan and Knight 2001), and have to be accounted for in the fire-model formulation. As such, they are beyond the scope of the present work. The measurement error is defined as the departure between the wind speed that would have been measured at fire location during the fire experiment (without the fire), referred to as the fire-front wind $\left(\mathrm{u}_{\mathrm{f}}\right)$, and the measured wind speed at measurement location $(\mathrm{s})\left(\mathrm{u}_{\mathrm{m}}\right)$ (Sullivan and Knight 2001; Pimont et al. 2017), averaged over the same time period. The conventional approach is that $\mathrm{u}_{\mathrm{m}}$ is typically measured above bare ground, in an open area at a reference height $h_{\text {ref }}$ (20 feet or $10 \mathrm{~m}$ ), as described in Fisher and Hardy 1976). It is expected to highly depend on the surrounding obstacles (typically the canopy located in the upwind side of the open area), so that it is recommended that the measurements are done at more than $7 h$ from the trailing edge, with $h$ the height of the canopy (Fisher and Hardy 1976). In practice, this measured wind is assumed to be representative of the wind at $h_{r e f}$ above the canopy in the fire plot (Andrew 2012), which we refer later to as the fire wind $\left(u_{f}\right)$. This reference wind is typically converted to a wind at the height of interest through a Wind Adjustment Factor -WAF- (Andrews 2012), which depends on the fire modelling approach. A widespread assumption is to convert the fire wind to a mid-flame-height wind; in this context, calculation of WAF has important implications (e.g. Albini and Baughman 1979; Massman et al. 2017). As this height of interest potentially depends on the fire spread conditions, which determines the flame height, the scope of the present paper will be limited to the fire wind $\left(\mathrm{u}_{\mathrm{f}}\right)$, which is defined as the average wind at $h_{r e f}$ above the canopy within the fire plot, and its relationship with the measured wind $\left(\mathrm{u}_{\mathrm{m}}\right)$ in the open, which conventional approaches assume it should represent.

To a large degree, the question of wind measurement representativeness, although critical, has seldom been addressed. The measurement error can be decomposed in two subcomponents (Hastie 2009). The first one is the error due to "bias", which is caused by the difference between the expectation of the measured wind and the expectation of the fire wind (which is what we would obtain by averaging replications of the experiment under a constant weather). To the best of our knowledge, there is apparently not much scientific support to the assumption that $u_{m}$ is equal to the wind at $h_{r e f}$ above the canopy. According to Fisher and Hardy (1976), measurement in open area can be replaced by measurement at "obstacle $+h_{r e f}$ " height, "if the ground is densely covered with rocks, brush, or small trees, increase the height of the anemometer by the average height of the ground cover." There is hence a potential bias associated with the fact that the wind at $h_{r e f}$ in the open would be equal to the wind at $h_{r e f}$ above the canopy and the magnitude of this bias might varies when changing canopy properties (e.g. height, Leaf Area Index, etc).

Another bias in real-world experiments arises from safety fuel breaks which often surround shrub or forest plots. In reality, the fuel break located in the upwind side of the fire plot almost certainly affects the wind profile, which requires some distance to adjust from an "open" profile to a "fire plot" profile (e.g. in Pimont et al. 2009; Pimont et al. 2011). As a result, it is likely that the fire wind $u_{f}$, at $h_{r e f}$ above the actual fire plot, differs from the wind that would be measured at $h_{r e f}$ above a canopy, especially for the part of the fire plot located at a short distance from the plot's leading edge. From now, we will refer to $u_{t h}$ (for theoretical wind) for the wind at $h_{r e f}$ above a long homogeneous canopy. 
The second subcomponent of error is due to "variance" (or variability) in both fire and measured winds. Even if the expectations of the fire wind (at $\mathrm{z}=h+h_{\text {ref }}$ in the fire plot, which represents the wind truly experienced by the experimental fire) and the measured wind (at $h_{r e f}$ in the open) were equal (i.e. no bias), their mean values over the duration of an actual fire experiment is expected to differ because of instantaneous fluctuations of the wind. Such an impact of variance has been studied through an experimental approach by Sullivan and Knight (2001) and a numerical approach by Pimont et al. (2017). Both studies were based on comparison between wind measurements made at distant locations below homogeneous canopies, so that average winds over long periods were expected to be equal at both locations. These studies revealed that, in fact, the average winds typically differ over the duration of a fire experiment, which is typically short, causing measurement error, often on the order of $+/-$ $30 \%$. In both studies, the duration and the extent of fire experiments, the number of sensors and the measurement heights were all critical factors influencing the degree of consistency between measured and fire winds. These studies, however, focused on the variance problem in a context which differs slightly from actual fire experiments, as both fire and measured winds were estimated below a homogeneous canopy, in which variability is expected to be much larger than in the open or above a canopy. The combination of measurement error due to both bias and variance has to date never been studied in a context close to actual fire experiments. In the present study, we used Large-EddySimulations (LES) of wind flows to estimate these two subcomponents of error from wind flow simulations, typically corresponding to the ICFME experiment (Taylor et al. 2004).

\section{Method}

We employed the HIGRAD/FIRETEC model to compute Large-Eddy-Simulations (LES) of wind flows over fire plots (corresponding to virtual fire experiments), as in Pimont et al. (2017). Wind flow simulations over both homogeneous canopy and open-to-forest transitions with the HIGRAD/FIRETEC model have been validated against detailed field experiments, in terms of both average wind profiles and turbulent profiles (Pimont et al. 2009).

The forest canopy was representative of the ICFME experiment (Taylor et al. 2004) and modelled with the FuelManager software from inventory data and allometric relationships for the different species (Pimont et al. 2016). Fuel breaks of various widths were designed in the landscape (in blue, in Fig. 1), so that simulated wind flows could be used to simulate measured wind, theoretical wind and fire wind at selected heights over fire experiments.

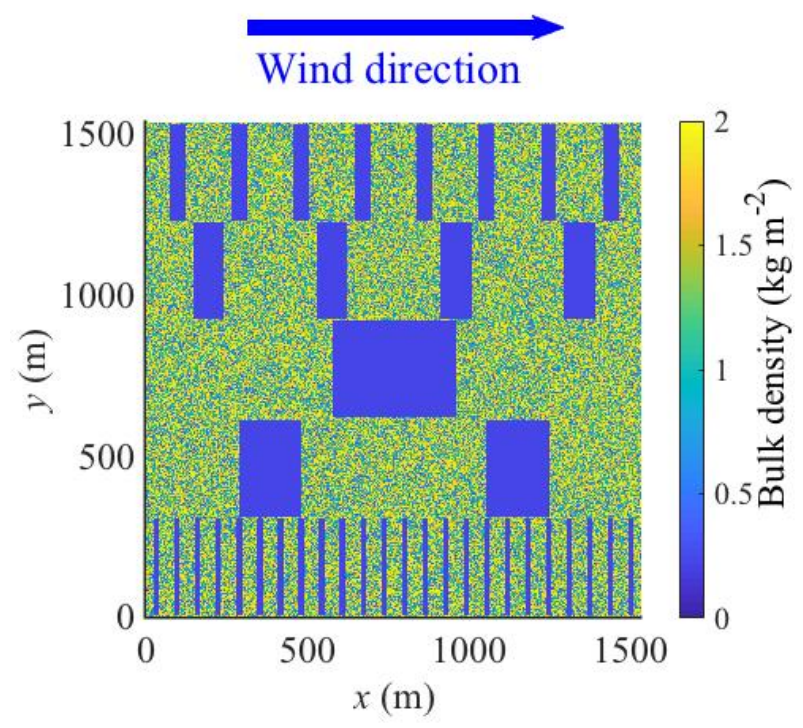

Figure 1 - Planimetric view of the fuel map (expressed in fuel bulk density), illustrating different spacing between the safety breaks (in blue, represented with very low fuel loads). This design enables comparison of simulated winds in virtual fire plots (within the canopy) and at sensor locations (within fuel breaks) to evaluate the wind measurement error in various conditions of fuel break widths, depending on the location of the fire plot in the fuel map. 
Simulated data were used to determine the sensitivity of these wind values to each configuration and to compute the resulting bias, which depends on the location of the sensor, the length of the open area and the location of the fire plot. We then compared the variance of both measured and fire wind to provide a comprehensive understanding of wind measurement error in fire experiments.

\section{Wind measurement bias}

Figure 2 shows the horizontal wind profiles in the streamwise direction, simulated at several heights in the case of a large open area $384 \mathrm{~m}$ across (shown close to the center in Fig. 1). In Figure 2, the $x$ axis is labelled with 0 at the end of the first canopy block, so that the labels correspond to the distance from this trailing edge. Close to the ground (at $z=20$ feet, in black) and at the top of the canopy (at $h=16.1 \mathrm{~m}$, in green), the wind accelerated over the open area, before slowing down when entering in next canopy block (at $d>384 \mathrm{~m}$ ). The $20 \mathrm{ft}$ curve shows that wind velocity at a distance equal to $7 \mathrm{~h}$ from the trailing edge, as recommended in Fisher and Hardy (1976) led to a measured wind of $3 \mathrm{~ms}^{-1}$, whereas the measured wind reached $4.1 \mathrm{~ms}^{-1}$ at $d=20 h$. This suggests that $7 h$, which is the distance suggested by Fisher and Hardy (1976), is too small to reach an "open" wind value, for which the canopy to forest transition requires at least $30 h$ to fully adjust to the "open" environment (e.g. Pimont et al. 2011). The red curve represents the wind at $h+20 \mathrm{ft}$, which is shown to be significantly increased above the open area with respect to the theoretical wind $u_{t h}$ at $\mathrm{z}=h+h_{\text {ref }}$ above a homogeneous forest, $u_{t h}=4.3 \mathrm{~ms}^{-1}$. Moreover, the wind at $h+20 \mathrm{ft}$ just after the open area (at $2 h$ from the canopy leading edge) further increases up to $5.4 \mathrm{~m} / \mathrm{s}$, and then gently returns to its theoretical value $u_{t h}$ at only 7 to $8 h$ from the canopy leading edge. In contrast, the blue curve shows that the mean wind speed at $z=3 h$ was not much influenced by the open area. Unfortunately, such a height is too high for practical measurements with traditional anemometers.

Typically, if the measurement were made at $d=7 h$ in the open and the fire plot was within the first $100 \mathrm{~m}$ after the leading edge of the second canopy block, the fire wind would be on the order of $75 \%$ larger than the measured wind. However, if the wind was measured at $d=20 h$ and the fire was ignited at more than $200 \mathrm{~m}$ for the leading edge, the bias would be of only $5 \%$. This figure thus illustrates the importance of the location of both sensor(s) and fire plot and how this location affects the consistency of the measurement of the ambient wind.

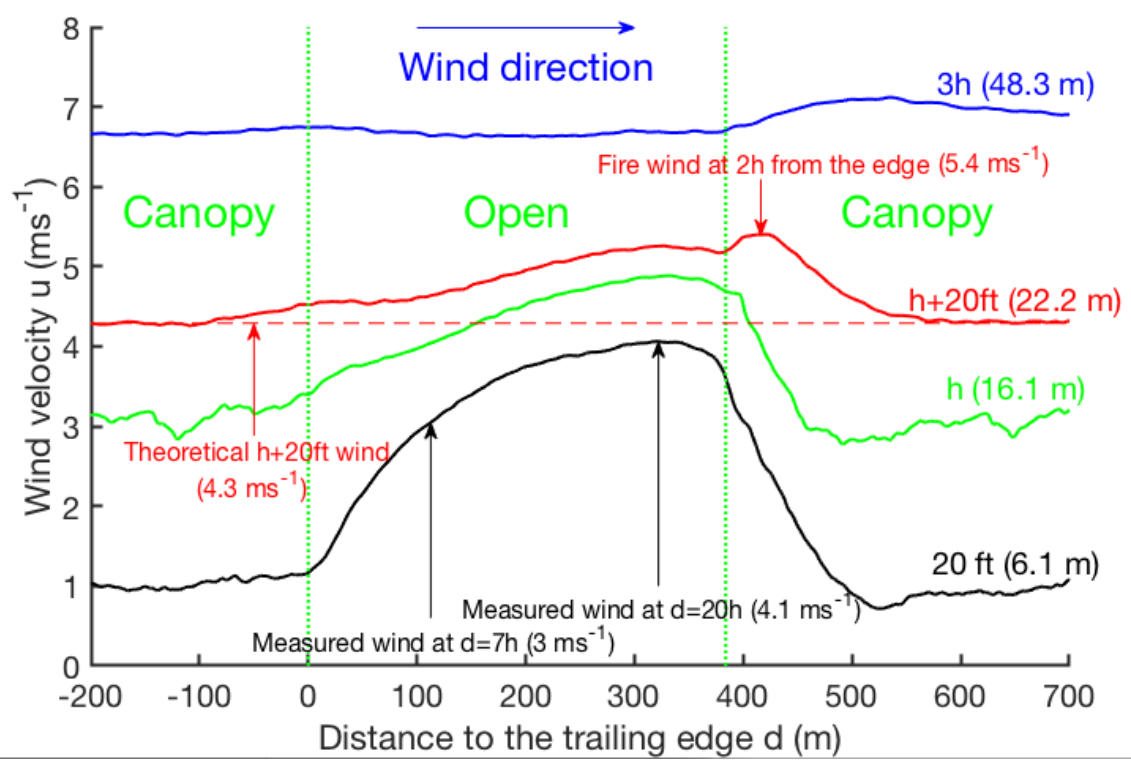

Figure 2 - Horizontal wind profiles at several heights over the $384 \mathrm{~m}$ open area ( $z=20 \mathrm{ft}$, in black; $z=h$ (canopy height), in green; $z=h+20 f t$ in red and $z=3 h$ in blue). The red dashed line corresponds to the wind speed at 20 ft above the canopy far from the open area, which is often referred to as the theoretical wind at h+20ft. The wind velocity at $20 \mathrm{ft}$ (in black) is strongly affected by the presence of the fuel break and has not converged after $d=7 \mathrm{~h}$. 
In Figure 2, the open area is very long (384 $\mathrm{m}$, which is on the order of $25 \mathrm{~h}$ ). In practice, open areas in forest are often much shorter. Figure 3 is similar to Figure 2, but for a shorter break $(96 \mathrm{~m}$, on the order of $6 h$, which corresponds to the four safety breaks located around $y=1100 \mathrm{~m}$, in Fig. 1). In this case the wind measured at $d=5 h$ from the edge would be $2.8 \mathrm{~ms}^{-1}$, which is much lower than the theoretical wind speed $\left(4.4 \mathrm{~ms}^{-1}\right)$. However, the shorter break induced a smaller impact on the fire wind after the break, which was much closer to the theoretical wind than after the large open area. In the present configuration, a measurement at $d=5 h$ would lead to an underestimation by $68 \%$ of the fire wind.

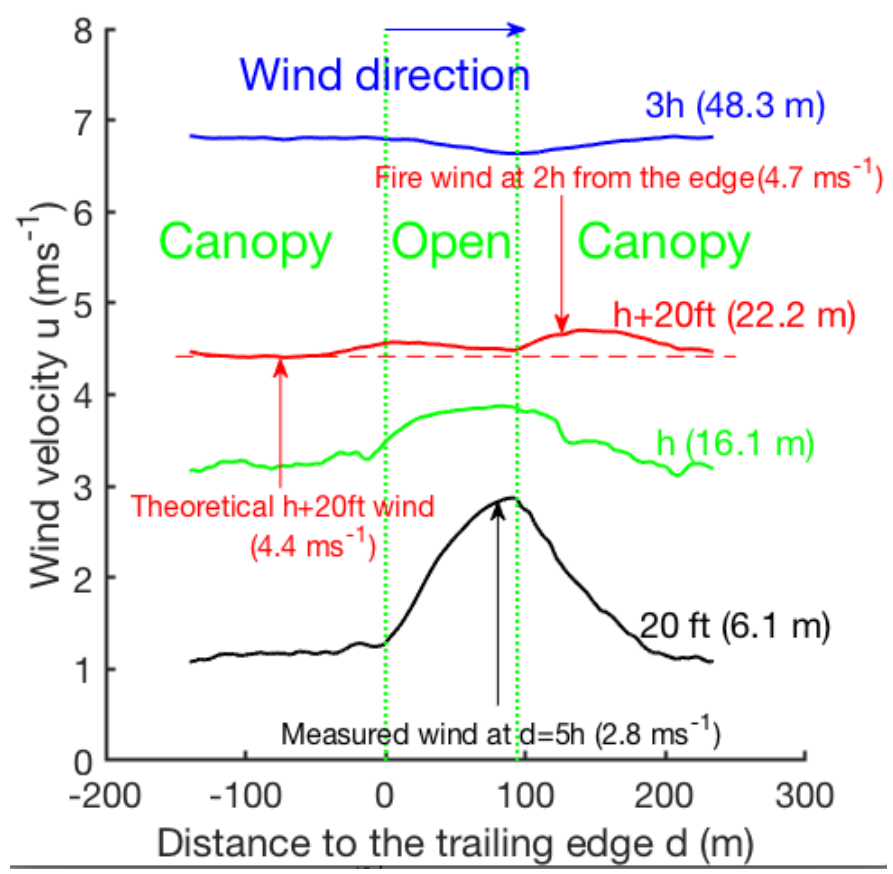

Figure 3 - Same figure as figure 2, but for the 96 m open area. ( $z=20 f t$, in black; $z=h$ (canopy height), in green; $z=h+20 f t$ in red and $z=3 h$ in blue). The red dashed line corresponds to the wind speed at 20 ft above the canopy far from the open area, which is often referred to as the theoretical wind at $h+20 f t$.

\section{Wind measurement variance}

In this subsection, we evaluated the variance in a specific configuration, in which the sensors were located at $20 \mathrm{ft}$ above the ground and at a distance $d=7 \mathrm{~h}$ from the trailing edge of the largest (centered) safety break of Fig. 1 (as recommended in Fisher and Hardy, 1976). The fire plot was in the forest area located downwind to this break (starting just after the leading edge of the second forestry block, see Fig. 1). We simulated fire winds, corresponding to mean wind at the location of a virtual fire spreading at a constant rate of spread (ROS, here $0.5 \mathrm{~ms}^{-1}$ and $\left.1 \mathrm{~ms}^{-1}\right)$ in square fire plots of a given size (50, 100 and $200 \mathrm{~m}$ ), which led to virtual experiments with durations between 50 and $400 \mathrm{~s}$. We also computed the measured wind from different numbers of virtual sensors (from one to five sensors). The design was inspired from Pimont et al. (2017), who provide more details on the method.

Figure 4 shows the comparison between fire and measured winds for the three fire plot sizes, assuming that the fire spreads at ROS $=0.5 \mathrm{~ms}^{-1}$. As expected from the previous subsection, the fire wind at 20ft above the canopy was on average much larger than the measured wind at 20ft above the ground at $d=7 \mathrm{~h}$ from the trailing edge (the no-bias line is in dashed black). 

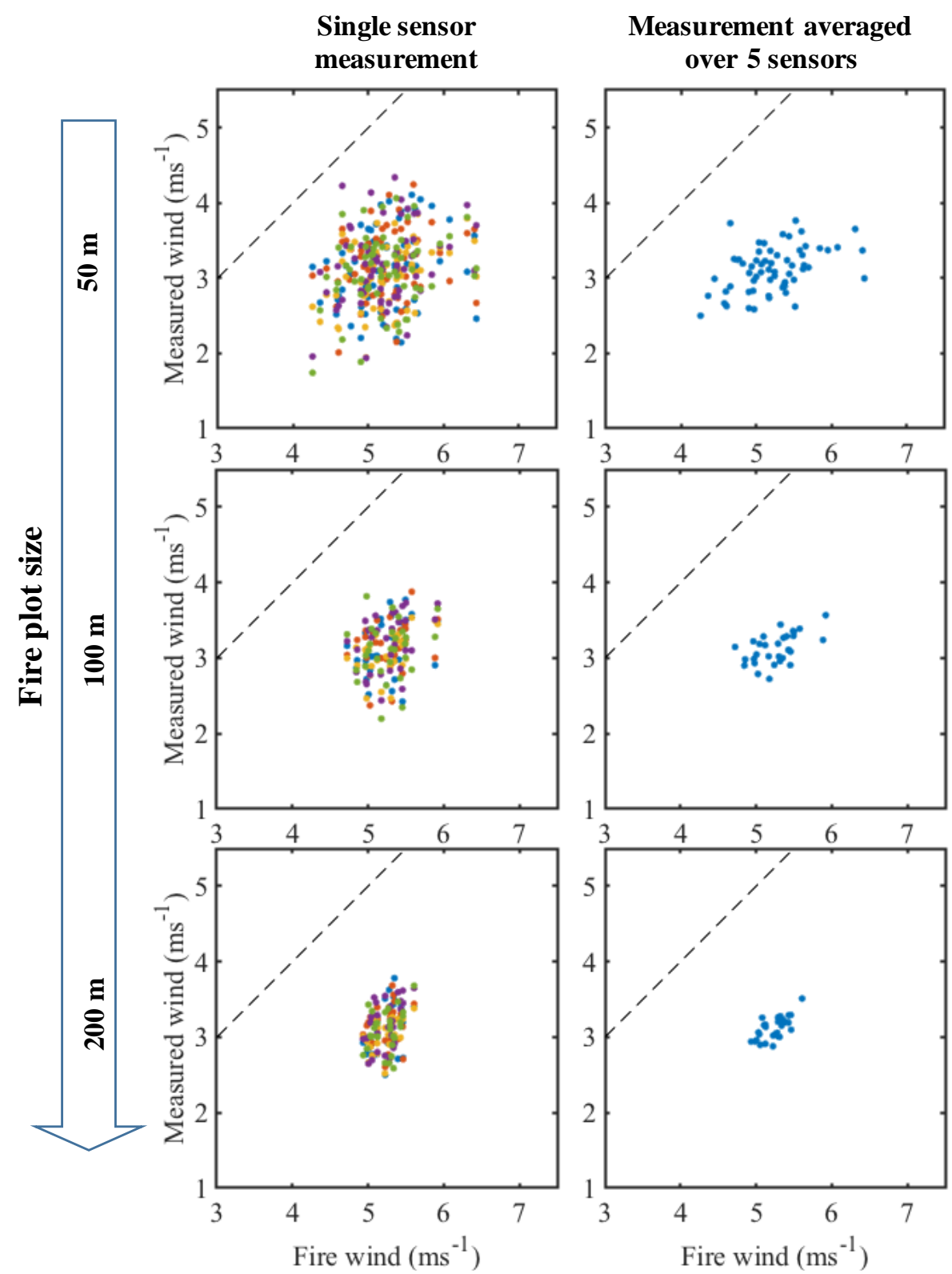

Figure 4 - Comparison between measured and fire wind speeds simulated during different virtual fire experiments in fire plots of size 50, 100 and $200 \mathrm{~m}$. As ROS $=0.5 \mathrm{~ms}^{-1}$, the durations of these experiments are respectively 100, 200 and 400s. Increasing plot size (and thus experiment duration) strongly reduced the variability of both measured and fire wind speed. Also averaging over 5 sensors, rather than using only one, strongly reduced the measured wind variability.

Here, we focus on the variability of fire and measurement winds, which were obviously not much correlated, because of the short duration of the fire experiments (as already reported by Sullivan and Knight 2001 and Pimont et al. 2017). This variability was very high when measurements were made on a single sensor and with the smallest fire plot $(50 \mathrm{~m})$ which also corresponded to a short experiment duration (100 s). Increasing the size of the plot reduced the variability in both measured and fire wind speed. Measurement wind variability was reduced by the number of sensors.

Figure 5 is similar to Fig 4, but for a faster $\operatorname{ROS}\left(1 \mathrm{~ms}^{-1}\right)$, which led to shorter experiment durations. As expected, the corresponding variability was much larger than for the shorter duration. 

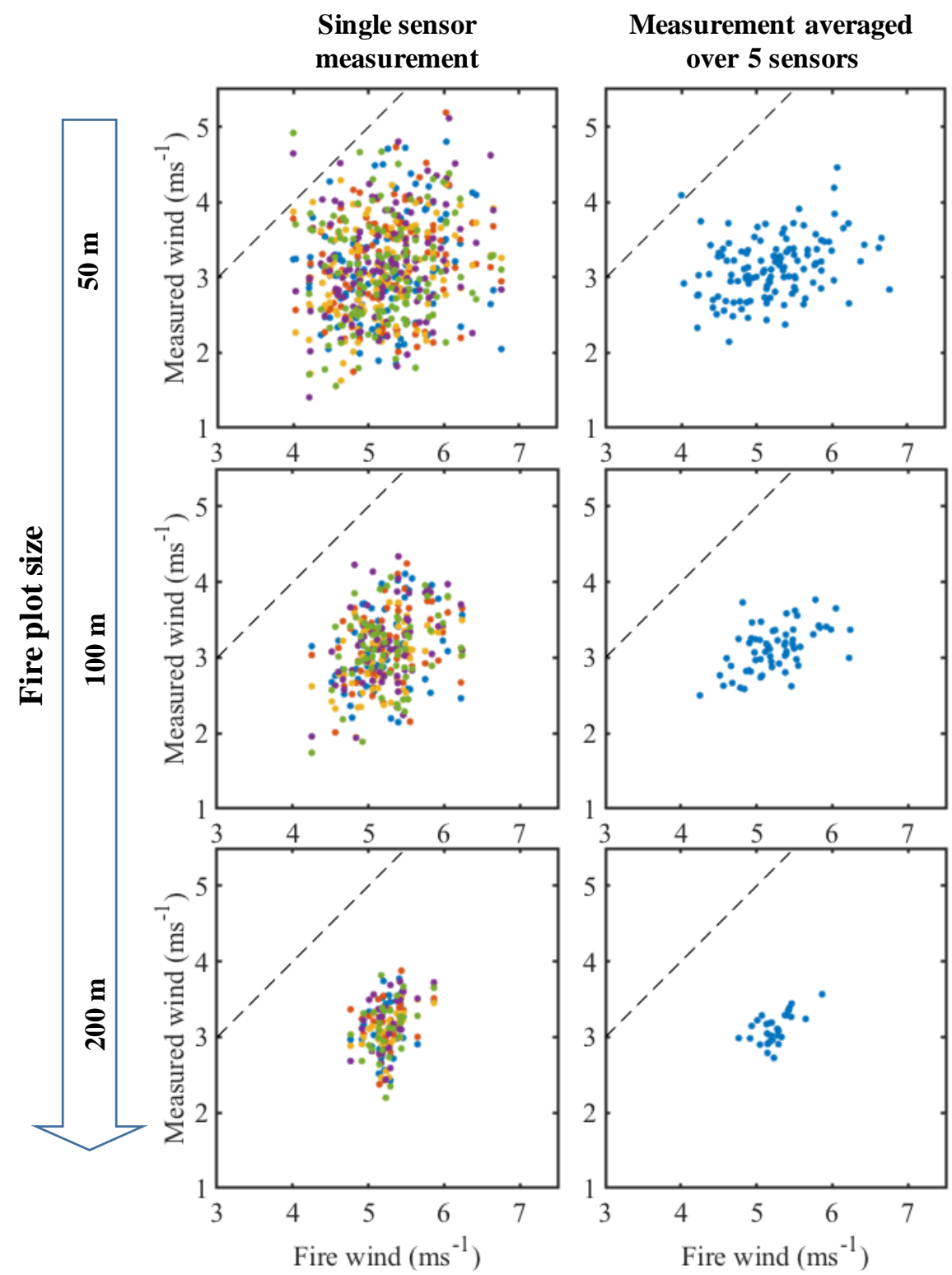

Figure 5 - Same figure as Fig. 4, but assuming a faster ROS $\left(1 \mathrm{~ms}^{-1}\right)$, and thus shorter experiment durations (50, 100 and 200s). The trends were similar as in Fig. 4, but much stronger variability was observed because of shorter averaging period.

\section{Discussion and conclusion}

The work presents an innovative analysis of the wind measurement error in fire experiments, by combining the two sources of error: the problem of wind representativeness (caused by the turbulent nature of the wind) and the heterogeneity bias, (caused by differences in physical environment between the location of wind measurements and where the fire spreads).

From both Fig. 2 and 3, we can recommend to set the fire plot after a small safety zone (6h or less), in order to limit the influence of the safety zone on the fire plot (to limit variations between the fire wind and the theoretical wind). Ideally, the fire line should be ignited at more than $2 h$ downwind to the leading edge, although this could raise practical problems. Regarding the measurement, the sensor would be placed in a very large open area (ideally larger than $20 \mathrm{~h}$ when available), on the side of the fire plot, to enable the convergence of the open wind, used to estimate the ambient wind. However, as it is often not practically doable, we recommend to measure the distance to the trailing edge and to 
describe the upwind canopy (at least the height, and eventually the Leaf Area Index and the canopy cover), so that horizontal wind adjustment factors (HWAF) can be applied, to convert the wind measured at a given distance to the actual open wind, at long distance from the edge. This is of major importance because for the same ambient wind (and thus a same expected ROS), the measured wind would be very significantly different if the measurements were made at $5 h, 7 h, 20 h$ or $30 h$ during the fire experiment. This could have been a significant source of bias in previous experiments, in which measurements were not necessarily homogeneous in terms of distance to the edge. We think that simulated or measured- HWAF could help to increase the quality of empirical fire data and to better understand the residuals in empirical models, which are in general fairly wide, as the mean absolute error is at best on the order of $+/-30 \%$ (Cruz and Alexander 2013).

Our analyses of measurement and fire wind variability confirmed the strong influence of the fire plot size, the experiment duration and the number of sensors, consistent with previous work in Sullivan and Knight (2001) and Pimont et al. (2017). The main benefit of the present work was to address this problem of wind representativeness in a context which was more realistic, as the previous studies compared measured and fire winds estimated below canopies and in horizontally homogeneous configurations. Clearly, our analyses demonstrate that the wind measurement accuracy is poor in fire plots of $50 \mathrm{~m}$ ( 3 to $4 h$ ) and limited in those of $100 \mathrm{~m}$ (6 to $7 h)$. For these specific experiments, and especially when only one sensor was available, the wind measurement variability can be reduced by averaging the measured wind on longer period than the one of the experiment (a few minutes before and after). There is no way, however, to reduce the variability of the fire wind, meaning that we basically have no idea of what the actual wind really was in the fire plot during the experiment (from 4 to $7 \mathrm{~ms}^{-1}$ ). According to our computations, a fire plot size on the order of $200 \mathrm{~m}(12 h)$ seems to be satisfactory, provided that the fire does not spread too fast. We would like to point that the magnitude of the ambient wind velocity was found to be a major factor of variation in measurement accuracy in homogeneous canopies (Pimont et al. 2017) and such a result should hold in the present more realistic context. It is thus expected that the -relative- variability of both fire and measured winds would be higher in the case of lower ambient wind.

This study also illustrates how physics-based models can be used to improve the knowledge regarding wind measurement in field experiments. More detailed analyses in a variety of fuel types and safety break design should help to provide general guidelines regarding the number of sensors and eventually to suggest some correcting factors such as the HWAF, described above. Finally, we did not investigate how the fire wind (at $h_{\text {ref }}$ above the fire plot) relates to the mid-flame height wind, even if this vertical wind adjustment is another source of both bias and variance, which could be the scope of future investigations.

\section{References}

Albini FA, Baughman RG, Intermountain Forest and Range Experiment Station (Ogden, Utah) (1979) 'Estimating windspeeds for predicting wildland fire behavior' (Intermountain Forest and Range Experiment Station, Forest Service, U.S. Dept. of Agriculture,: Ogden, Utah:) doi:10.5962/bhl.title.68710.

Andrews PL (2012) 'Modeling wind adjustment factor and midflame wind speed for Rothermel's surface fire spread model.' (United States Department of Agriculture/Forest Service, Rocky Mountain Research Station)

Cheney NP, Gould JS (1995) Fire growth in grassland fuels. International Journal of Wildland Fire 5, 237-247. 
Taylor SW, Wotton BM, Alexander ME, Dalrymple GN (2004) Variation in wind and crown fire behaviour in a northern jack pine black spruce forest. Canadian Journal of Forest Research 34, 1561-1576.

Cruz MG, Alexander ME (2013) Uncertainty associated with model predictions of surface and crown fire rates of spread. Environmental Modelling \& Software 47, 16-28. doi:10.1016/j.envsoft.2013.04.004.

Fischer WC, Hardy, CE (1976) 'Fire-weather observers' handbook'. Agricultural handbook 494. (USDA Forest Service: Washington, DC). 152 p.

Hastie T, Tibshirani R, Friedman JH (2009) 'The elements of statistical learning: data mining, inference, and prediction.' (Springer: New York, NY)

Massman WJ, Forthofer JM, Finney MA (2017) An improved canopy wind model for predicting wind adjustment factors and wildland fire behavior. Canadian Journal of Forest Research 47, 594-603. doi:10.1139/cjfr-2016-0354.

Pimont F, Dupuy J-L, Linn RR, Dupont S (2009) Validation of FIRETEC wind-flows over a canopy and a fuel-break. International Journal of Wildland Fire 18, 775. doi:10.1071/WF07130.

Pimont F, Dupuy J-L, Linn RR, Dupont S (2011) Impacts of tree canopy structure on wind flows and fire propagation simulated with FIRETEC. Annals of Forest Science 68, 523-530. doi:10.1007/s13595-011-0061-7.

Pimont F, Parsons R, Rigolot E, de Coligny F, Dupuy J-L, Dreyfus P, Linn RR (2016) Modeling fuels and fire effects in 3D: Model description and applications. Environmental Modelling \& Software 80, 225-244. doi:10.1016/j.envsoft.2016.03.003.

Pimont F, Dupuy J-L, Linn RR, Parsons R, Martin-StPaul N (2017) Representativeness of wind measurements in fire experiments: Lessons learned from large-eddy simulations in a homogeneous forest. Agricultural and Forest Meteorology 232, 479-488. doi:10.1016/j.agrformet.2016.10.002.

Sullivan AL, Knight IK (2001) Estimating error in wind speed measurements for experimental fires. Canadian Journal of Forest Research 31, 401-409. doi:10.1139/cjfr-31-3-401. 